\title{
Code Switching in Teaching Physical Education
}

\author{
Aileen M. Daran Ed. D., Dennis N. Daran, Ph. D. \\ Faculty, Laguna State Polytechnic University, Santa Cruz, Laguna, Philippines
}

\begin{abstract}
In the real world where everyone communicates to be understood, the ability to speak English has become an advantage of an individual since English has essentially become the "universal second language" internationally. It is now a common place for many universities across the world to teach courses in English as well the native language of their country.
\end{abstract}

One of the most apparent consequences of this has been the widespread use of code-switching, where multiple languages are spoken in everyday communication. As such, code-switching is often seen as a social as well as a linguistic medium. Code switching isn't always bad. But as with anything, it should be done in moderation.

Allowing code switching as a bridge between familiar and unfamiliar vocabulary often helps students get more comfortable conversing spontaneously in the target language. Students just feel more comfortable when they're addressed in their native language, and it makes it easier to build relationships with them.

This paper attempts to demonstrate the impact and effects of code-switching in bilingual classes such as teaching Physical Education. As Baker (2007) emphasized, users of code-switching show impressive cognitive, linguistic, and social skills. In his view code-switchers may be preserving the meaning of their original statement by overcoming the lack of a suitable word in the second language (Baker, 2007: 56-57).

After this study was conducted and documented, it was found that there was a significant difference in teaching Physical Education using English and Taglish as a medium of instruction. A large number of situations are considered to be causes of code-switching, one of which is linked to gaps in students' linguistic ability. Often the target language simply does not have the exact word needed in order to maintain a discussion smoothly, and code-switching is necessary.

Keywords: code switching, Taglish, controlled, experimental, bilingual

\section{Background of the Study:}

Languages are in constant process of change in sound, in form and in meaning so long as they are spoken. The evolution of language is generally from complex forms to simpler and more freely combinable elements; thus, French has a fewer inflections than Latin and Latin fewer than Sanskrit. English is structurally one of the simplest languages.

Code switching occurs when a speaker alternates between two or more languages in the context of a single conversation. Multilingual speakers of more than one language sometimes use elements of multiple languages when conversing with each other. Thus, code switching is the use of more than one linguistic variety in a manner consistent with the syntax and phonology of each variety.

Li (2008) in her study, defines classroom code switching as the alternating use of more than one linguistic core in the classroom participants such as teachers and students. 
In multilingual country like the Philippines, it is customary for us to see a fusion of one or more languages, dialects and styles spoken and also written forms. Hence, being able to converse in more than just one language to another is very predictable within the society itself. In the same manner, setting concrete boundaries around classroom, code switching can be use effectively and prevent confusion or sloppiness among students.

With the advancement of era of multimedia and technology, code switching is no longer restricted to spoken form but code switching can be observed in written form too. We are aware that with a more developed communication system globally, code switching can be spotted in varying interactions such as chat rooms, forums, blogs and social media like Facebook and YouTube as Montes-Alcala (2007) would put it that more and more different patterns and styles of code switching are emerging and people code switch more often in written form of language and this includes one of the infamous medium, blog.

This study pushed the researcher to find out what was better in communicating and learning of an individual in the field of Physical Education. The researcher wanted to find out if code switching has a significant effect on the learning of the students. As a Physical Education instructor, the result of this study may be of great help to adapt in a classroom setting, more so, the Physical Education instructors of the Laguna State Polytechnic University may get informed with the strategies on how to have an interactive classroom setting using code switching but not compromising the need of the students to learn the international language.

\section{Statement of the Problem:}

The main purpose of this research was to determine the effect of code switching to the controlled and experimental group of students.

Specifically, this research sought answers to the following questions:

1. What is the level of teaching Physical Education in terms of:

1.1 English

1.2 Taglish

2. What is the level of teaching Physical education as perceived by:

2.1 Controlled

2.2 Experimental

3. Is there a significant difference between teaching Physical Education as perceived by both respondents?

Research Hypothesis: There is no significant difference between teaching Physical Education as perceived by both respondents?

\section{Literature Review}

The different definitions for code-switching are cited by experts. Code-switching involves the use of multiple languages, where speakers of additional languages incorporate alternate linguistic elements into their source language. As such, two or more languages may be spoken alternately during a conversation. Chan et al (2009) usefully describe code-switching as "the intra-sentential switching of two different languages in a spoken utterance" (Chan et al, 2009: 281).

Gemperz (1982) defined code-switching as "the juxtaposition within the same speech exchange of speech passages belonging to two different grammatical systems, while Myers-Scotton's (2006) general definition 
concerned the "use of two language varieties in the same conversation." They both stated that it occurs when bilinguals alternate between two languages during one interaction, maintaining the monolingual features between them.

According to Naved Z. (2015), the English language was England's language originally, but through the expansion and propagation of the British Empire, the Language was brought to many countries of exploration which then the secondary and even the primary language of some former British colonies such as the United States, Canada, Australia and India. As of now, not only the countries touched by British Imperialism uses it, but also a lot of businesses and cultural spheres influenced by those countries. It is also the language used by Hollywood and the language of the business and accountancy. Due to high demand, it is a very necessary language to be learned by everyone.

As a result, English language became the Universal language of the world. In order to communicate and understand people in other country, people should know how to speak in English Language. According to Trudgill (2000), "speakers switch to manipulate, to influence, to define the situation they wish, and to convey nuances of meaning and personal intention. Through this, it may be considered that CS can be used for selfexpression and is a way of modifying language for the sake of personal intentions.

In addition, code-switching can have a positive impact in an academic context. An important teaching skill is the ability to transfer knowledge to students in a clear and efficient manner, and so code-switching can be a useful tool in the classroom for both teachers and students (Bista, 2010: 1). Code-switching may also be used to emphasize a point, or to add more force to a phrase. On a psychological level, learners often code-switch when they feel tired or angry. For example, when the speaker is in a good mood, the appropriate word or expression in their second language is easily identified. However, if the speaker is distracted in any way, they may find it difficult to grasp the correct word.

Another function of code-switching is that it may be used in order to build intimate interpersonal relationship among members of a bilingual community. This can relate to allowing students to code switch when they have difficulty continuing a conversation in the target language.

Code switching may also be used to emphasize a point, or to add more force to a phrase. On a psychological level, learners often code switch when they feel tired or angry. For example, when the speaker is in good mood, the appropriate word or expression in their second language is easily identified. However, if the speaker is distracted in any way, they may find it difficult to grasp the correct word.

In addition, code switching can have a positive impact in an academic context. An important teaching skill is the ability to transfer knowledge to students in a clear and efficient manner, and so code switching can be a useful tool in the classroom for both teachers and students.

There are also personal and social reasons for code-switching in that one's choice of words can represent an expression of their personality. Allatson (2007) suggests factors that can lead to code-switching as location, class, gender and age. In addition, the relationship between the speakers; the formal or informal nature of the conversation and the social status of the speakers can also be factors (Allatson, 2007: 73).

However, in the study of Borlongan Arianne M. (2012), they found out that students learning are not hindered by the use of ETCS (English Tagalog Code Switching) in lectures. Additionally and more fascinatingly, students may even perform better in a language they are more comfortable with. Unfortunately, at present, educational policy-makers, educational managers, classroom teachers, and even accrediting agencies of 
school are not yet prepared to accept the reality of multilingualism in the Philippines, that not only do students have positive attitudes towards CS but CS also fosters learning.

Porciuncula, LA (2011) also states that " the use of English both in the local and international domains is far from diminishing. These days, it is not unusual to heat Filipino children talking in English, teenagers in serting English expressions in conversations, and professionals carrying out their daily tasks in the English language. Hence, while I understand the reasons and sentiments that argue against the use of English in Philippine education, I don't think we should stop using it altogether, given that it has become apart of the typical Filipino's linguistic repertoire."

\section{Methodology}

Sixty PE major students from the College of Teacher Education, Laguna State Polytechnic University were included in this study. The controlled and experimental group has 30 students respectively. They are students from Santa Cruz Main Campus. The controlled group was given a lecture in English and the experimental group were taught with code switching.

After a series of lecture, the researcher asked help from other PE instructor to distribute among students (controlled and experimental group) the basic questions in a form of questionnaire.

After the time allotted, the researcher collected the questionnaire and tabulated for the result.

\section{Results and Discussion}

Table 1. Mean Level of English Language as a medium of teaching Physical Education

\begin{tabular}{|l|l|l|l|}
\hline English Language & Mean & SD & Interpretation \\
\hline $\begin{array}{l}\text { 1. I understand the lesson much better when } \\
\text { English language is used. }\end{array}$ & 3.83 & 0.66 & often \\
\hline $\begin{array}{l}\text { 2. It helps me to communicate better with my } \\
\text { teacher and classmates. }\end{array}$ & 3.69 & 0.93 & often \\
\hline $\begin{array}{l}\text { 3. Talking in English during discussion helps me } \\
\text { enhance my communication skills. }\end{array}$ & 4.41 & 0.68 & always \\
\hline $\begin{array}{l}\text { 4. I am interested in the topic or lesson the teacher } \\
\text { explains using English Language. }\end{array}$ & 4.07 & 0.70 & often \\
\hline $\begin{array}{l}\text { 5. I prefer English Language as a medium of } \\
\text { communication }\end{array}$ & 4.00 & 0.76 & often \\
\hline OVERALL MEAN & $\mathbf{4 . 0 0}$ & $\mathbf{0 . 7 5}$ & often \\
\hline
\end{tabular}

Table 1 is the level of English Language as a medium in teaching Physical education. The first statement "I understand the lesson much better when English language is used" has a mean level of 3.93 and SD of 0.66 is verbally interpreted as "Often." The next statement," It helps me to communicate better with my teacher and classmates" has a mean of 3.69 and SD of 0.93 verbally interpreted as "Often." The third statement "Talking in English during discussion helps me to enhance my communication skills" has a mean of 4.41 and SD of 0.68 verbally interpreted as "Always". The fourth statement, "I am interested in the topic or lesson when the teacher explains using English language," has a mean of 4.07 and SD of 0.70 verbally interpreted as "Often." The last statement, I prefer English language as a medium of communication," has a mean of 4.00 and SD of 0.76 verbally interpreted as "Often." The over - all weighted mean 4.00 of the level of English language as a medium in teaching Physical Education is verbally interpreted as "Often." 
Table 2. Mean Level of Taglish as a medium in Teaching Physical Education

\begin{tabular}{|l|l|l|l|}
\hline Taglish & Mean & SD & Interpretation \\
\hline $\begin{array}{l}\text { 1. I can express my thoughts much better when I } \\
\text { use Taglish. }\end{array}$ & 4.66 & 0.48 & Always \\
\hline $\begin{array}{l}\text { 2. Translating something that I cannot understand } \\
\text { in English to Filipino helps me in understanding } \\
\text { the lesson. }\end{array}$ & 4.31 & 0.81 & Always \\
\hline $\begin{array}{l}\text { 3. I understood the lesson when the teacher uses } \\
\text { taglish. }\end{array}$ & 4.52 & 0.63 & Always \\
\hline $\begin{array}{l}\text { 4. I can explain a certain topic very well using } \\
\text { Taglish }\end{array}$ & 4.72 & 0.45 & Always \\
\hline 5. I prefer using Taglish during class discussion. & 4.55 & 0.69 & Always \\
\hline OVERALL MEAN & 4.55 & 0.61 & Always \\
\hline & & & \\
\hline
\end{tabular}

Table 2 is level of Taglish as a medium in teaching Physical Education. The first statement "I can express my thoughts much better when I use Taglish" has a mean of 4.66 and SD 0.48 verbally interpreted as "Always". The second statement "translating something that I cannot understand in English to Filipino helps me in understanding the lesson" has a mean of 4.31 and has SD of 0.81 verbally interpreted as "Always." The third statement "I understand the lesson when the teacher uses Taglish" has a mean of 4.52 and SD of 0.63 verbally interpreted as "Always". The fourth statement "I can explain a certain topic very well using Taglish" has a mean of 4.72 and SD of 0.45 is verbally interpreted as "Always". The last statement "I prefer using Taglish during class discussion" has a mean of 4.55 and SD of 0.69 is verbally interpreted as "Always". The over all weighted mean 4.55 of the level of Taglish as a medium in teaching Physical education is verbally interpreted as "Always".

LEGEND:

\begin{tabular}{|l|l|l|}
\hline SCALE & RANGE & INTERPRETATION \\
\hline 5 & $4.20-5.00$ & ALWAYS \\
\hline 4 & $3.40-4.19$ & OFTEN \\
\hline 3 & $2.60-3.39$ & SOMETIMES \\
\hline 2 & $1.80-2.59$ & SELDOM \\
\hline 1 & $1.00-1.79$ & NEVER \\
\hline
\end{tabular}

\section{Summary of Data}

\begin{tabular}{|l|l|l|l|}
\hline Medium of Instruction & Mean & SD & Interpretation \\
\hline English Language & 4.00 & 0.75 & Often \\
\hline Taglish (code-switched) & 4.55 & 0.61 & Always \\
\hline
\end{tabular}

The table shows the difference between using English and Taglish as a medium of instruction in teaching Physical Education. It further shows that teaching in English has a mean of 4.00 and SD of 0.75 verbally interpreted as "often" while teaching in Taglish has a mean of 4.55 and SD of 0.61 verbally interpreted as "Always."

Therefore, with regards to the statements above, it signifies that the null hypothesis was rejected and accept the alternative hypothesis that there is a significant difference between using English and Taglish as medium of instruction in teaching Physical education. 


\section{Conclusion}

The study was an attempt to bring attention and determine the code switching and its effect among learners of Bachelor of Secondary Education major in Physical Education in Laguna State Polytechnic University Sta Cruz Main Campus.

Based on the findings of the researcher, code switching can help the researcher say easily what they want to convey. Using Taglish as a medium of teaching Physical Education leads to a more interactive classroom setting where students can easily transmit words and thoughts. With the help of code switching, it has a good effect to learners to improve their communication skills.

\section{Recommendations}

1. Future researches may look into the inclusion of efficacy of teaching through code switching in the academic performance of the respondent.

2. Teachers may set concrete boundaries around classroom code switching to use it effectively and to prevent sloppiness among students.

3. Teachers may allow students to code switch to help them feel encouraged and supported.

4. Teachers may allow students to code switch when they have difficulty continuing a conversation in the target language.

5. Further researches on code switching may be conducted to establish its importance in a classroom interaction.

\section{References:}

Allatson, P., 2007. Key terms in Latino/a cultural and literary studies, Oxford: Blackwell.

Bista, K., 2010. 'Factors of Code Switching among Bilingual English Students In the University Classroom: A Survey'. English for Specific Purposes World, Volume 9, pp.1-19.

Baker, C., 2007. A Parents' and Teachers' Guide to Bilingualism, Clevedon: MPG Books.

Borlongan, A.M. (2012) "Reflecting on the Use of Code-Switching in Philippine Education Today." TESOL Journal 7: 78-80

Chan, J. Y. C., H. Cao, P. C. Ching, T. Lee, 2009. 'Automatic Recognition of Cantonese-English CodeMixing Speech'. Computational Linguistics and Chinese Language Processes, September, pp.281-304.

Gemperz, J. (1982) Discourse Srategies. Cambridge, MA: Cambridge University Press

Myers-Scotton, C. (2006) Multiple Voices: An Introduction to Bilingualism. Blackwell Publishing.

Li, D. C. S., 2008. 'Understanding Mixed Code and Classroom Code-Switching: Myths and Realities'. New Horizons in Education, December, pp.75-87.

Naved, Z (2015). “The Importance of the English Language in Today's World: Linguistics, Humanities, Owlcation". Retrieved from;

https://owlcation.com/humanities/importanceofenglishlanguages

Porciuncula, LA (2011) "English as a Medium of Instruction in Philippine Education: A History. Retrieved from:

https://www.academia.edu/24102460/English as a medium of Instruction in Philippine Education A History 